\title{
Global Health Research, Anthropology and Realist Enquiry Methodological Musings
}

\section{Sara Van Belle}

\begin{abstract}
Aвstract: In this article, I set out to capture the dynamics of two streams within the field of global health research: realist research and medical anthropology. I critically discuss the development of methodology and practice in realist health research in low- and middle-income countries against the background of anthropological practice in global health to make claims on why realist enquiry has taken a high flight. I argue that in order to provide a contribution to today's complex global issues, we need to adopt a pragmatic stance and move past disciplinary silos: both methodologies have the potential to be well-suited to an analysis of deep layers of context and of key social mechanisms.
\end{abstract}

KeYwords: ethnography, global health, low- and middle-income countries, medical anthropology, realist evaluation

In recent years, realist enquiry became increasingly popular in health programme evaluation and research as well as in health systems and policy research in low- and middle-income countries (LMIC), often conducted by researchers from these countries (Abejirinde et al. 2018; Kwamie et al. 2014; Prashanth et al. 2014). In the process, questions were raised about the similarities and differences between realist enquiry and anthropological enquiry. Both approaches are case-oriented and compare across cases. Cases are selected based on their richness and variation. Both approaches consider the embeddedness of social action in context as a sine qua non of their application: the context triggers certain mechanisms, which in turn produce social action. Finally, both methods use retroduction (backwards tracing from an empirically observed phenomenon to the mechanisms that produced this phenomenon) to a certain extent to explain social phenomena.

Realist evaluation is an evaluation methodology from the family of theory-based evaluations, and is increasingly used to evaluate interventions in the field of healthcare and international development
(Van Belle et al. 2016). It aims at opening the black box between intervention and outcome by developing explanations that take into account actors, contexts and mechanisms in a configurational approach. Recently, realist evaluation has evolved into a broader field of enquiry, moving beyond programme evaluation and encompassing reviews, syntheses and realist research (Emmel et al. 2018). Health professionals and health practitioners are also attracted to this type of enquiry, applying it to the evaluation and researching of operational issues. Part of the appeal of realist enquiry is that it provides a systematic approach to learning and that it suits complex interventions rather well. According to Geoff Wong and colleagues (2010), complex interventions 'consist of multiple human components that interact in a nonlinear fashion to produce outcomes which are highly context-dependent'. In this definition, actors (and their unpredictable behaviour), their interactions and their relationships make an intervention 'complex' (Marchal et al. 2012).

Other methods commonly used to engage with the complexity of health systems and the delivery of 
healthcare in LMIC include social science research methods, such as grounded theory, participatory action research, and ethnography (Green and Thorogood 1994; Liamputtong 2012). Ethnography has been successfully applied to make sense of and improve upon the management of health systems and the implementation of health policies. Due to its practitioners' engagement with meaning, applied medical anthropology has a critical role to play in enabling community-based health systems that are founded upon people's values and beliefs. Indeed, the Declaration of Alma-Ata of 1978, with its focus on the engagement of communities, provided a role for anthropologists in facilitating the responsiveness of healthcare services to community needs (Manderson et al. 2016b).

In this article, I discuss critically the current development of methodology and practice in realist health research in LMIC against the background of applied anthropological practice in global health to make claims on why realist enquiry has been taken up so readily. I set out to capture the dynamics in these methodological streams within the field of current global health research. I argue that realist enquiry has been readily embraced because its philosophical position between positivism and social constructivism presents an easier entry point for biomedically trained practitioners than does applied anthropological enquiry. I do not claim to be comprehensive in detailing disciplinary evolution - this is merely a starting point for discussion.

\section{An Anthropologist's Personal Journey (in Methodology)}

I trained as a cultural anthropologist and political scientist in the mid-1990s at the height of the cultural studies movement in the United Kingdom and the emergence of the field of post-colonial studies (Gandhi 1998). These influences transformed the curriculum of the master's degree in anthropology at my Belgian university, a change exemplified by the fact that the master's degree title 'anthropology' was dropped and changed to 'comparative cultural studies'. This move broadened the domain of enquiry to include, amongst other important topics, the study of migration. Not much later came the start of a reinvention of anthropology as a discipline towards a 'globalised' anthropology, which expanded its research subject and explored subjects such as migrant identities, global networks, the digital revolution, gender, and social exclusion, leaving behind its colo- nial past (Hannerz 2016). After some meandering, I ended up in a department of public health of a European global health research institute in the mid-2000s as a lecturer in medical anthropology and sociology. I found that medical anthropology practice applied to health service delivery in LMIC was strangely devoid of the evolution described above. What happened with post-colonialism in global health research?

\section{Gridlock in Global Health Research: The Enduring Struggle between Disciplines}

Within tropical medicine (and in its leading schools in the United Kingdom), anthropology (in the Anglophone tradition) was traditionally understood as one of the disciplines that contributed to disease control programmes (Pool and Geissler 2005). Originally, medical anthropologists were to identify the local meanings of disease, translate these into communication and health-promotion strategies and manage the relationships with the community in the implementation of programmes (Heggenhougen and Pedersen 1997; Koss-Chioino 1997; Manderson 1998; Sommerfeld 1998). Anthropologists were henceforth 'increasingly employed in departments of tropical medicine, hygiene and international health with an increasing focus on community-based research in infectious disease control' (Heggenhougen and Pedersen 1997). The historical trajectories of global health research institutions contributed to this state of affairs, effectively 'locking them in' to a particular practice of interdisciplinary interaction (Foxon 2002). For some, social scientists were 'being employed as the handmaidens of biomedicine' (Parker et al. 2016). Interdisciplinary relationships and disciplinary power appeared to be deeply engrained in academic institutions as part of their organisational culture, and they were particularly resistant to change.

Compared to the Anglophone tradition of applied medical anthropology, a different route seems to have been taken by the Francophone tradition, where the discipline of medical sociology integrated with anthropology, thereby dampening the biomedical dominance in the field (Carricaburu and Ménoret 2004). Francophone socio-anthropologists carried out research on, for instance, health systems and power within healthcare organisations (Jaffré and Olivier de Sardan 2003). Typically, they followed the path of critical studies, incorporating the theories of Michel Foucault and Pierre Bourdieu (Fassin 2000) and critiquing the instrumentalisation of anthropology (Gruénais 2012). Interesting recent developments in- 
clude current work on socio-ecological systems (Sterk et al. 2017), on ecohealth (Dakubo 2010), and on the emerging discourse on planetary health and sustainability science (Brouselle and Butzbach 2018; Pattanyak and Haines 2017). Embracing an agenda broader than health and firmly embedded in complexity science, these approaches address global problems and appear to be less vexed by interdisciplinary struggle (Montuori 2013).

After having described the gridlock between two 'cultures' in much of Anglophone global health research - a dominant biomedical one and an applied medical anthropological one - I now turn to realist enquiry, which is perceived by some as building a bridge between the two because of its position between positivism and social constructivism (Gilson 2012; Goertz and Mahoney 2012).

\section{Realism: An Aha Erlebnis in Global Health Research?}

Realist evaluation (Pawson and Tilley 1997) is an approach based on scientific realism that combines a realist ontology with a weak relativist epistemology. Methodologically, it seeks to establish causation by identifying the causal configuration of intervention, actors, context and mechanisms that underlies outcomes. It is theory-driven in the sense that realist research starts by eliciting the programme theory underlying the topic of investigation. This programme theory is best considered as a hypothesis that is built upon exploratory research, reviews of existing evidence and/or the assumptions of key stakeholders. Being method-neutral, realist researchers combine qualitative and quantitative methods of data collection and analysis in order to 'test' the hypothesis the choice of methods follows from the research question. The ICAMO configuration is the heuristic used to identify how the intervention I, in specific context $\mathrm{C}$, through the actions of actors $\mathrm{A}$, triggers mechanisms $\mathrm{M}$ to produce an outcome $\mathrm{O}$ (Marchal et al. 2018; Van Belle 2014). Research studies end by refuting, confirming or adapting the initial programme theory, which then sets off the next study in a process of accumulation through which at some point middle-range theories can emerge. Indeed, the work of Ray Pawson and Nick Tilley (1997) harkens back to the concept of middle-range theory as defined by Robert Merton (1949). From the realist perspective, one particular study will generate plausible explanations for what took place. Through accumulation, the researcher will identify the conditions in which the intervention triggers the mechanisms that explain how people responded to the intervention (or not) and thus created the outcome, thereby increasing the external validity of the results. This is why it is important to test the programme theory across a number of sites. Figure 1 presents the realist research cycle. I refer you to Sara Van Belle and colleagues (2016) and to Sara Van Belle and colleagues (2017) for more details.

Initially, realist evaluation was not readily adopted in global health research - its early applications were in the fields of social policy and crime prevention. One of the first publications in health to present the potential of the methodology of a realist review was that by Pawson and colleagues in the Journal of Health Services Research and Policy in 2005, in which the authors explicitly considered healthcare interventions as complex interventions working on complex social systems. This acknowledgement of the complexity of healthcare interventions coincided in the United Kingdom with the critique on evidence-based medicine and the randomised controlled trial (RCT) as the gold standard study design (Greenhalgh and Russell 2009; Plsek and Greenhalgh 2001; Sturmberg and Martin 2013). In other sectors of social policy in the United Kingdom and in the United States, RCTbased decision-making has been questioned within a broader critique of new managerialism and performance management (Radin 2007).

About ten years ago, the complexity of health interventions and the subsequent need for alternative

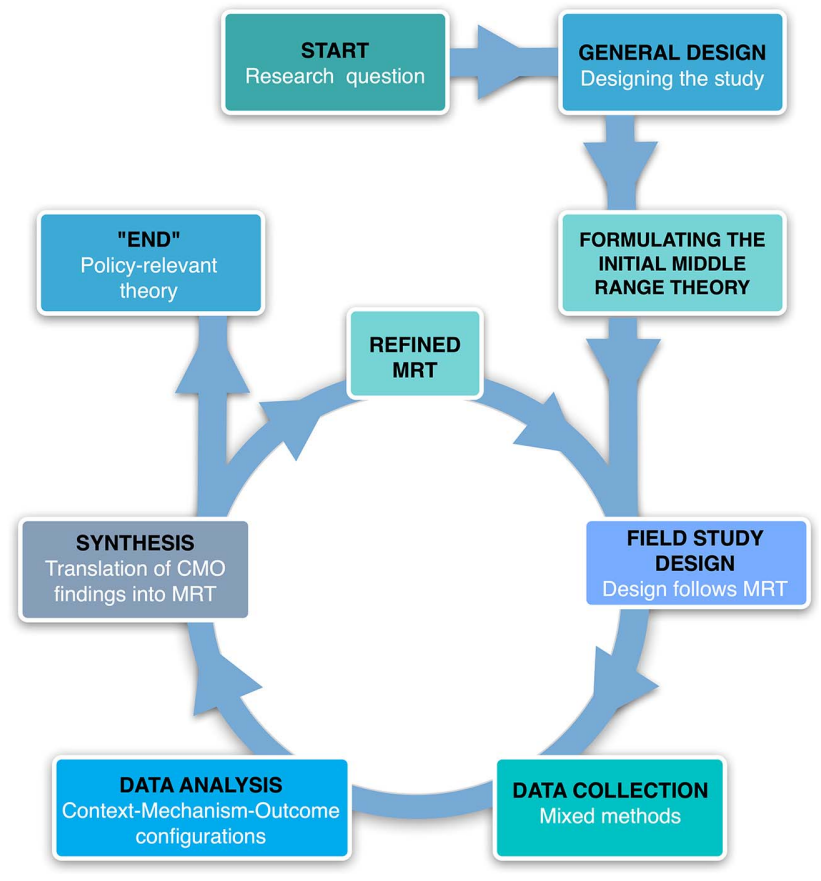

Figure 1. The realist research cycle (Marchal et al. 2012) 
evaluation designs started resonating within the world of global health policy and systems research. This brought realist evaluation, as an alternative evaluation design, to the fore (Brainard and Hunter 2016) next to other complexity-oriented approaches (Blanchet et al. 2017; Tracy et al. 2018). Finally, the much-used Health Policy and Systems Research: A Methodology Reader, which was developed by Lucy Gilson for the World Health Organization and the Alliance for Health Policy and Systems Research, contributed to its increasing recognition in the world of global health research (Gilson 2012).

\section{From Realist Evaluation to Realist Research}

Social scientists will be aware that the use of middlerange theory and social mechanisms and the focus on configurational causation instead of successionist causation are elements of analytical sociology (Harré and Moghaddam 2016; Hedström and Bearman 2009). Realist evaluation indeed sets out to provide an answer to the critique that social science research is too descriptive and not sufficiently explanatory. Realist evaluation (RE) and synthesis are now expanding into realist research. The scope of the most recent RE conference in Brisbane in 2017 included realist research as did the recently published reference work Doing Realist Research (Emmel et al. 2018). This reflects the broader application of RE in global health research, for instance in research on policy implementation, accountability (Van Belle 2014), programme implementation (Mukumbang et al. 2018, 2016), hospital management (Marchal 2011), district management (Kwamie 2016), capacity development (Prashanth et al. 2014), and health volunteerism (Vareilles et al. 2015).

\section{The Position of (Medical) Anthropology in the Current Global Health Landscape}

Before I start analysing the characteristics of applied (medical) anthropology in global health, I will first explain the qualifiers that I will use. Traditionally, medical anthropology has explored social, cultural and other dimensions of health and illness. I will refer to '(medical) anthropology in global health' to stress its broad, transdisciplinary, cross-cultural and critical character, examining research issues at the interface of health and well-being, culture, society, and the environment while zooming in on people's particular, context-specific experiences (Panter-Brick and Eggerman 2018).

While I argued above that realist evaluation is an innovative methodological approach to research and evaluation in global health, this vision is certainly not shared by all. Some medical anthropologists might ask: 'What's new? We've been doing this all along'. However, many biomedically trained researchers, who relate to its blend of positivist ontology and relativist epistemology, find RE attractive. It also speaks to programme managers and decision-makers in global health who recognise the limitations of project cycle management, logical framework approaches and impact evaluations. Indeed, RE entered into the field of global health research proposing alternative ways to evaluation and evidence synthesis so as to inform decision-making. The catch phrases 'opening the black box' (Astbury and Leeuw 2010; Harachi et al. 1999) and 'what works for whom in what respects to what extent in which contexts and how' captured the mood within a substantial part of the global health research and evaluation communities.

This perception of innovation is arguably related to how anthropology has been viewed in a global health field traditionally dominated by the biomedical sciences. I will discuss some explanations of the relatively modest profile of anthropology without developing the entire historical trajectory of anthropology in global health. Others have reviewed this topic recently (Manderson et al. 2016;b Panter-Brick and Eggerman 2018). First, the (stark) difference between the worlds of anthropological practice and of biomedical sciences and clinical research may have made it challenging for biomedical researchers and practitioners in global health to actively engage with anthropology. Second, much published ethnography does not seem to fit the recent guidelines regarding qualitative health research (Lewin et al. 2015) or the standards for the use of qualitative evidence in health decision-making, which require the 'clear exposition of methods of data collection and analysis' (Mays and Pope 2000). Indeed, the actual research process within anthropological practice is often only cursorily described in published research, thus remaining implicit. Finally, medical anthropologists have portrayed themselves (and have been perceived as) a separate disciplinary community within global health research mainly 'collaborating with clinical researchers and epidemiologists' (Hardon and Pool 2016). From my personal experience, such disciplinary positioning is a defence against the dominant biomedically oriented organisational culture in many global health research institutes. This specific identification on the basis of discipline is central to the medical anthropology practice, as evidenced in the introduction of The Routledge Handbook of Medical Anthropology (Manderson et al. 2016a). It both mirrors and is 
a reaction to the unique disciplinary positioning of medical doctors.

Anthropological practice recently gained much ground in the global health landscape with the Ebola epidemic in West Africa in 2014-2015. The epidemic put the spotlight on the key role that anthropologists can play in social mobilisation and establishing community relationships (Brown et al. 2015; Sáez et al. 2014). An Ebola Response Anthropology Platform was developed, which detailed the contribution of anthropologists to the identification of cases, to the management of the deceased, and to the caretaking of the sick, as well as in the development of communication strategies and the development of preparedness strategies (Ebola Response Anthropology Platform 2018). In spite of this, some European anthropologists involved in the containment of the epidemic felt personally conflicted about their role, as was evident in some oral accounts and interventions provided at the 2015 European Association of Social Anthropologists (EASA) conference in Sussex (EASA Medical Anthropology Network and the RAI Medical Anthropology Committee 2015). One of the many ethical dilemmas surfacing in the West African Ebola outbreak was connected to (European) anthropologists being employed by international non-governmental organisations and humanitarian aid organisations to manage community relations. Supposedly subscribing - through their actions - to the values, cultures and operations of these organisations, anthropologists became somewhat uncomfortably entangled in the political and power dynamics of the humanitarian aid context (Venables and Pelecchia 2017). A number of anthropologists developed a critical reflection on what the contribution of anthropology should be in the containment of global epidemic outbreaks, with the discourse becoming more critical as time went on (Chandler et al. 2015; Hofman and Au 2017; Manca 2017; Minor 2017; Wilkinson et al. 2017).

\section{The Nature of Anthropological Enquiry and Its Position on Causality}

\section{Origins in Naturalism}

As opposed to realist research, the philosophical origins of anthropological practice lie with (semi-) naturalism: remaining true to the actual nature of the social phenomenon under study. This means that one aims to understand social life and the life-world from the perspective of the actors themselves (Hammersley and Atkinson 2007). Post-modernists and postcolonialists have rejected naturalism on the grounds that it is impossible to access the experiences of the 'other': they consider the 'other' as a social construct. Moreover, the post-colonial movement not only critiqued naturalism, it also rejected anthropology's origins, which it felt were deeply enmeshed with the colonial endeavour (Gandhi 1998; Hammersley 1992). It should be noted, however, that absolute naturalism has been rejected by most anthropologists, who argue that it is not possible to access social phenomena in their 'natural' setting in a direct way. Today, much of anthropological practice and ethnography seeks to combine a naturalistic ontology with a social constructivist epistemology. However, for some authors, these stances are not entirely compatible (Hammersley 2018).

Scientific realism, the philosophical basis of RE, shares naturalism's respect for empirical phenomena. Naturalism and realism also share the viewpoint that methods must be assessed in terms of their fit with the subject of study. Martyn Hammersley (1992), in his book What's Wrong with Ethnography?, noted that ethnography has some surprisingly realist undertones.

\section{Causal Analysis in Ethnography}

One of the core methods of anthropological practice is ethnography, which was once described by Jack Katz (2001) as 'luminous description', a reworking of Clifford Geertz's 'thick description'. Katz argues that ethnography does not only aim at describing social action - an often-heard critique being that ethnography is merely describing and not explaining - but also at understanding causal relationships. In this view, the ethnographer is interpreting social life and producing 'thick interpretation'. She or he is searching for hidden meanings underlying social action that subjects cannot fathom easily: 'In any case, before thrashing about in arguments over whether we must or must not bring causal analysis to ethnography, we should first appreciate how subtly and usefully we are already doing it' (Katz 2001, p. 449). Katz proposes different criteria to evaluate the explanatory content of ethnography. First, ethnography should ideally be case-oriented. Second, it should explain causal linkages through methods such as contrasting different cases, portraying the unusual or the counter-intuitive, using longitudinal data (e.g. life histories), or using retroduction to explain a social phenomenon (Katz 2001). 


\section{Differences, Similarities (and Weaknesses)}

There are a number of similarities and differences between realist enquiry and anthropological enquiry. Both approaches are case-oriented and compare across cases. Cases are selected based on their richness and variation. In their realist studies, both Bruno Marchal (2011) and Van Belle (2014) used a contrastive case study design to test an initial programme theory that was developed on the basis of the literature. Marchal compared well-performing hospitals with bad performers to investigate the role of management, while Van Belle contrasted a local urban health system with a rural one to examine public accountability. Both approaches consider the embeddedness of social action in context as a sine qua non: mechanisms are triggered only in some contexts and thus lead to social action. Finally, both use retroduction to explain social phenomena, even if Katz (2001) and Hammersley (2018) argue that this explanatory potential must be developed further in ethnography.

Arguably, developing a better interface between realist research and anthropology would be beneficial in several ways. Methodological experts researching complex problems in complex systems need to explore how to build theory in 'applied fields focused on action' which lack the 'theoretical sensitivity necessary (to build) conceptually rich theory' (Glaser 1995). Both ethnography and realist research could contribute to a deeper understanding of context in global health research and action. A better way to analyse layers of context (i.e. the interactions between micro-, meso- and macro-levels) is required to avoid misguided methodological individualism or reductionism underlying programmatic global health choices. Understanding 'deep' context is also necessary in one of the more recent themes in global health research - namely, intersectionality and its impact on health outcomes (Romero 2018). How do we analyse the impact of cross-generational and historical layers of social injustice and inequities? How do we strengthen health systems in an inclusive way to meet the universal health coverage goal of 'leaving no one behind' (WHO Regional Office for Africa 2017)? How to better translate the lived experience of vulnerable groups into participatory action? What are the mechanisms underlying social inclusion (Liamputtong 2007)? And what about the role of culture(s) and our position as cross-cultural researchers?

A fundamental difference with realist research is that anthropology as a discipline does not share realism's layered ontology and generative causality. Realist explanations of social practice are grounded in generative causality with social mechanisms at the core (Maxwell 2012): underlying social mechanisms triggered by specific action generate social action in a specific context. The analytical strategy is rooted firmly in a specific philosophy of science, as explained above. This is less so in the case of anthropology.

Arguably, ethnography would benefit from a more open and transparent stance on how one reaches the 'why' via the 'how', to avoid the criticism of 'descriptive capture', certainly when one is combining a RCT with ethnography (Glaser 2001; Hardon and Pool 2016). In a policy environment still dominated by positivist perspectives, researchers need to ensure methodological rigour and be careful not to produce 'fake handbags' or diluted versions of the original methodology (Hanefeld 2016). This would help in taking its well-deserved place in global health research. Despite the fact that realists consider social structure as ontologically real, in practice many researchers tend to focus excessively in their analysis on mechanisms at an individual, cognitive level. As a result, they tend to fall back into methodological individualism. Realist enquiry would benefit from further deepening of the concepts and understandings of meso- and macro-level mechanisms. Ethnography could contribute to such a deeper understanding through exploring the generative nature of social structures, such as, for example, social exclusion (Porter 1993).

\section{Conclusion: A Convergence of Approaches?}

In this article, I set out to describe and compare how realist research and medical anthropology evolved in the field of global health research and how they are being adopted by researchers in this field. Both approaches speak to the social complexity of health and allow for a flexible approach to its study. There is a long-standing tendency to use standardised, fixed, step-wise research designs (Hanefeld 2016). This is reflected by a recent call from the Department for International Development / Wellcome Trust Joint Initiative on Epidemic Preparedness for the development of standardised social science research protocols (Wellcome Trust 2018). The complex nature of health, health systems and healthcare, however, demands research approaches that embrace causal 
complexity and allow for the use of flexible designs. It is here that both realist research and ethnography, or more broadly, anthropology, thrive. Furthermore, both approaches may contribute to better theory development, a recognised priority in a field where a focus on actionable results often leads to research that is under-theorised and built on assumptions that could easily be dispelled on the basis of social science theories.

Within the field of global health research, it is likely that we will see some convergence of the two approaches - even when their philosophical origins are different. As the field of global health research is focused on applied research and action, and researchers are expected to be able to work in multi-disciplinary teams, a pragmatic stance towards the application of methodology is required, and this may stimulate exploring the interface between realist research and anthropology. We are at a point in time where we should leverage the potential of realist research and contemporary anthropology to provide us a way out and into the baffling complexity of global issues.

\section{Acknowledgements}

Bruno Marchal, Isabelle Lange and Rodney Reynolds edited this article and made corrections at the final stage. To them, I offer my sincere thanks.

SARA VAN Belle is a cultural anthropologist and political scientist with a PhD in public health from the London School of Hygiene and Tropical Medicine (LSHTM). She is a senior research fellow at the Institute of Tropical Medicine, Antwerp, an honorary assistant professor at the LSHTM and a lecturer at Sciences Po Paris. Her research interests include accountability and governance within health systems and their implications for sexual and reproductive health and rights services in LMIC.

Email: svanbelle@itg.be

\section{References}

Abejirinde, I. O., M. Zweekhorst, A. Bardají, R. Abugnaba-Abanga ,N. Apentibadek, V. De Brouwere, J. van Roosmalen and B. Marchal, 'Unveiling the Black Box of Diagnostic and Clinical Decision Support Systems for Antenatal Care: Realist Evaluation', JMIR Mhealth Uhealth 6, no. 12: e11468. doi:10.2196/mhealth.11468.
Astbury, B. and F. L. Leeuw (2010), 'Unpacking Black Boxes: Mechanisms and Theory Building in Evaluation', American Journal of Evaluation 31, no. 3: 363382. doi:10.1177/1098214010371972.

Blanchet, K., D. De Savigny and T. Adam (eds.) (2017), Applied Systems Thinking for Health Systems Research: A Methodological Handbook (London: Open University Press).

Brainard, J. and P. R. Hunter (2016), 'Do ComplexityInformed Health Interventions Work? A Scoping Review', Implementation Science 11, no. 127. doi:10 .1186/s13012-016-0492-5.

Brouselle, A. and C. Butzbach (2018), 'Redesigning Public Health for Planetary Health', Lancet Planetary Health 2, no. 5: e188-e189. doi:10.1016/S25425196(18)30054-8.

Brown, H., A. Kelly, A. M. Sáez, E. Fichet-Calvet, R. Ansumana, J. Bonwitt . . . and N. Magassouba (2015), 'Extending the "Social": Anthropological Contributions to the Study of Viral Haemorrhagic Fevers', PLOS Neglected Tropical Diseases 9, no. 4. doi:10.1371/journal.pntd.0003651.

Carricaburu, D. and M. Ménoret (2004), Sociologie de la Santé: Institutions, professions et maladies (Paris: Armand Colin).

Chandler, C., J. Fairhead, A. Kelly, M. Leach, F. Martineau, E. Mokuwa ... and A. Wilkinson (2015), 'Ebola: Limitations of Correcting Misinformation', Lancet 385, no. 9975: 1275-1277. doi:10.1016/ S0140-6736(14)62382-5.

Dakubo, C. Y. (2010), Ecosystems and Human Health: A Critical Approach to Ecohealth Research and Practice (New York: Springer).

EASA Medical Anthropology Network and the RAI Medical Anthropology Committee, 'MAGic2015, Anthropology and Global Health: Interrogating Theory, Policy and Practice', 9-11 September 2015, University of Sussex, UK, Programme Booklet.

Ebola Response Anthropology Platform 2018, www.ebola-anthropology.net (accessed 14 July 2018).

Emmel, N., J. Greenhalgh, A. Manzano, M. Monaghan and S. Dalkin (eds.) (2018), Doing Realist Research (Los Angeles: Sage).

Fassin, D. (2000), 'Entre politiques du vivant et politiques de la vie: une antropologie de la santé', Anthropologie et Sociétés 24, no. 1: 95-116. doi:10 .7202/0156638ar.

Foxon, T. J. (2002), 'Technological and Institutional 'Lock-In' as a Barrier to Sustainable Innovation', ICCEPT Working Paper, November, http://www.iccept .ic.ac.uk/public.html (accessed 15 July 2018).

Gandhi, L. (1998), Postcolonial Theory: A Critical Introduction (New York: Columbia University Press). 
Gilson, L. (2012), Health Policy and Systems Research: A Methodology Reader (Geneva: Alliance for Health Policy and Systems Research).

Glaser, B. G. (ed.) (1995), Grounded Theory 1984-1994 (Mill Valley, CA: Sociology Press).

Goertz, G. and J. Mahoney (2012), A Tale of Two Cultures: Contrasting Quantitative and Qualitative Methods in the Social Sciences (Princeton, NJ: Princeton University Press).

Green J., Thorogood, N. (2004), Qualitative Methods for Health Research (London: Sage).

Greenhalgh, T. and T. Russell (2009), 'Evidence-Based Policy Making: A Critique', Perspectives in Biology and Medicine 52, no. 2: 304-318. doi:10.1353/pbm 0.0085 .

Gruénais, M. E. (2012), 'L'anthropologie sociale: Est-elle inapplicable?' Bulletin de l'APAD 34-36, https:// journals.openedition.org/apad/4109.

Hammersley, M. (1992), What's Wrong with Ethnography? Methodological Explorations (London: Routledge).

Hammersley, M. (2018), 'Ethnomethodological Criticism of Ethnography', Qualitative Research. doi:10.1177/1468794118781383.

Hammersley, M. and P. Atkinson (2007), Ethnography: Principles and Practice (London: Routledge).

Hanefeld, J. (2016), 'Advancing Global Health - The Need for (Better) Social Science', International Journal of Health Policy and Management 5, no. 4: 279-281. doi:10.15171/ijhpm.2016.13.

Hannerz, U. (2016), Writing Future Worlds: An Anthropologist Explores Future Scenarios (Basingstoke, UK: Palgrave Macmillan).

Harachi, T. W., R. W. Abbott, R. F. Catalano, K. P. Haggerty and C. B. Fleming (1999), 'Opening the Black Box: Using Process Evaluation Measures to Assess Implementation and Theory Building', American Journal of Community Psychology 27, no. 5: 711-731. doi:10.1023/A:1022194005511.

Hardon, A. and R. Pool (2016), 'Anthropologists in Global Health Experiments', Medical Anthropology 35, no. 5: 447-451. doi:10.1080/01459740.2016.1177 046.

Harré, R. and F. Moghaddam (eds.) (2016), Questioning Causality: Explorations of Cause and Consequence across Social Contexts (Santa Barbara, CA: ABC-CLIO).

Hedström, P. and P. Bearman (eds.) (2009), Oxford Handbook of Analytical Sociology (Oxford: Oxford University Press).

Heggenhougen, H. K. and D. Pedersen (1997), 'The Relevance of Anthropology for Tropical Public Health: A Historical Perspective', Tropical Medicine and International Health 2, no. 11: A5-10. PMID:9391518.
Hofman, M. and S. Au (2017), The Politics of Fear: MSF and the West-African Ebola Epidemic (Oxford: Oxford University Press).

Jaffré, Y. and J.-P. Olivier de Sardan (2003), Une médecine inhospitalière: Les difficiles relations entre soignants et soignés dans cinq capitales d'Afrique de l'Ouest (Paris: Karthala).

Katz, J. (2001), 'From How to Why: On Luminous Description and Causal Inference in Ethnography: Part 1', Ethnography 2, no. 4: 443-473. doi:10.1177/ 146613801002004001.

Koss-Chioino, J. D. and B. S. Hewlett (1997), 'Human Behaviour and Cultural Context in Disease Control', Tropical Medicine and International Health 2, no. 11: A3-5. PMID:9391517.

Kwamie, A. (2016), 'The Tree Under Which You Sit: Realist Approaches to District-Level Management and Leadership in Maternal and Newborn Health Policy Implementation in the Greater Accra Region, Ghana' (PhD diss., Wageningen University [The Netherlands]).

Kwamie, A., H. Van Dijk and I. A. Agyepong (2014), 'Advancing the Application of Systems Thinking in Health: Realist Evaluation of the Leadership Development Programme for District Manager DecisionMaking in Ghana', Health Research Policy and Systems 12, no. 29. doi:10.1186/1478-4505-12-29.

Lewin, S., C. Glenton, H. Minthe-Kaas, B. Carlsen, C. J. Colvin, M. Gülmezoglu . . . and A. Rashidian (2015), 'Using Qualitative Evidence in Decision Making for Health and Social Interventions: An Approach to Assess Confidence in Findings from Qualitative Evidence Syntheses (GRADE-CERQual)', PLOS Medicine 13, no. 6. doi:10.1371/journal.pmed.1001895.

Liamputtong, P. (2007), Researching the Vulnerable: A Guide to Sensitive Research Methods (London: Sage).

Liamputtong, P. (2012), Qualitative Research Methods (Melbourne: Oxford University Press).

Manca, M. C. (2017), "“Yassaba” or the Fear of Being Abandoned: Adapting Health-Promotion Messages to Incorporate Local Meanings in Guinée Forestière', Anthropology in Action 24, no. 2: 9-14. doi:10.3167/ aia.2017.240202.

Manderson, L. (1998), 'Applying Medical Anthropology in the Control of Infectious Disease', Tropical Medicine and International Health 3, no. 12: 1020-1027. PMID:9892288.

Manderson, L., E. Cartwright and A. Hardon (eds.) (2016a), The Routledge Handbook of Medical Anthropology (London: Routledge).

Manderson, L., E. Cartwright and A. Hardon (2016b), 'Introduction: Sign Posts', in L. Manderson, E. Cartwright and A. Hardon (eds.), The Routledge Handbook of Medical Anthropology (London: Routledge), 2-17. 
Marchal, B. (2011), ‘Why Do Some Hospitals Perform Better than Others? A Realist Evaluation of the Role of Health Workforce Management in Well-Performing Health Care Organizations' (PhD Diss., Free University of Brussels).

Marchal, B., G. Kegels and S. Van Belle (2018), 'Realist Evaluation in Health Policy and Systems Research: Theory Incarnate', in N. Emmel, J. Greenhalgh, A. Manzano, M. Monaghan and S. Dalkin (eds.), Doing Realist Research (London, Sage), 79-90.

Marchal, B., S. Van Belle, J. Van Olmen, T. Hoerée and G. Kegels (2012), 'Is Realist Evaluation Keeping Its Promise? A Literature Review of Methodological Practice in Health Systems Research', Evaluation 18, no. 2: 192-212. doi:10.1177/1356389012442444.

Maxwell, J. A. (2012), A Realist Approach for Qualitative Research (London: Sage).

Mays, N. and C. Pope (2000), 'Qualitative Research in Health Care: Assessing Quality in Qualitative Research', British Medical Journal 320, no. 7226: 50-52. PMID: 10617534.

Merton, R. K. [1949] (2007), ‘On Sociological Theories of the Middle Range', in C. Calhoun, J. Gerteis, J. Moody, S. Pfaff and I. Virk (eds.), Classical Sociological Theory (London: Blackwell Publishing), 449-459.

Minor, O. M. (2017), 'Ebola and Accusation: Gender Dimensions of Stigma in Sierra Leone's Ebola Response', Anthropology in Action 24, no. 2: 25-35. doi:10.3167/aia.2017.240204.

Montuori, O. (2013), 'Complexity and Transdisciplinarity: Reflections on Theory and Practice', World Futures 69, no. 4-6: 200-230. doi:10.1080/02604027 .2013.803349.

Mukumbang, F., B. Marchal, S. Van Belle and B. Van Wyk (2018), 'Unearthing How, Why, For Whom and Under What Health System Conditions the Antiretroviral Treatment Adherence Club Intervention in South Africa Works: A Realist Ttheory Refining Approach', BMC Health Services Research 18, no. 343: 1-15. doi:10.1186/s12913-018-3150-6.

Mukumbang F., S. Van Belle, B. Marchal and B. Van Wyk (2016), 'Towards Developing an Initial Programme Theory: Programme Designers' and Managers' Assumptions on the Antiretroviral Treatment Adherence Club Programme in Primary Health Care Facilities in the Metropolitan Area of Western Cape Province, South Africa', PLOS One 11, no. 8: e0161790. doi:10.1371/journal.pone.0161790.

Panter-Brick, C. and M. Eggerman (2018), 'The Field of Medical Anthropology', Social Science and Medicine 196: 233-239. doi:10.1016/j.socscimed.2017.10.033.

Parker, M., K. Polman and T. Allen (2016), 'Neglected Tropical Diseases in Biosocial Perspective', Journal of Biosocial Science 48, Suppl. 1: S1-S15. doi:10.1017/ S0021932016000274.

Pattanyak, S. K. and A. Haines (2017), 'Implementation of Policies to Protect Planetary Health', Lancet Planetary Health 1, no. 7: e255-e256. doi:10.1016/ S2542-5196(17)30115-8.

Pawson, R., T. Greenhalgh, G. Harvey and K. Walshe (2005), 'Realist Review - A New Method of Systematic Review Designed for Complex Policy Interventions', Journal of Health Services Research and Policy 10, Suppl. 1: 21-34. doi:10.1258/1355819054308530.

Pawson, R. and N. Tilley (1997), Realistic Evaluation (London: Sage).

Plsek, P. E. and T. Greenhalgh (2001), 'Complexity Science: The Challenge of Complexity in Health Care', British Medical Journal 323, no. 7313: 625-628. doi:10.1136/bmj.323.7313.625.

Pool, R. and W. Geissler (2005), Medical Anthropology (Maidenhead, UK: Open University Press).

Porter, S. (1993), 'Critical Realist Ethnography: The Case of Racism and Professionalism in a Medical Setting', Sociology 27, no. 4: 591-609. doi:10.1177 $\% 2 F 0038038593027004003$.

Prashanth, N., B. Marchal, N. Devadasan, G. Kegels and B. Criel (2014), 'Advancing the Application of Systems Thinking in Health: A Realist Evaluation of a Capacity Building Programme for District Managers in Tumkur, India', Health Research Policy and Systems 12, no. 42. doi:10.1186/1478-4505-12-42.

Radin, B. (2007), Challenging the Performance Movement: Accountability, Complexity and Democratic Values (Washington, DC: Georgetown University Press).

Romero, M. (2018), Introducing Intersectionality (London: Polity Press).

Sáez, A. M., A. Kelly and H. Brown (2014), ‘Notes from Case Zero: Anthropology in the Time of Ebola', Somatosphere, http://somat osphere.net/2014/09/ notes-from-case-zero-anthropology-in-the-time-ofebola.html (accessed 19 September 2018).

Sommerfeld, J. (1998), 'Editorial: Medical Anthropology and Infectious Disease Control', Tropical Medicine and International Health 3, no.12: 993-995. doi:10.1046/j.1365-3156.1998.00342.x.

Sterk, M., I. A. van de Leemput and E. T. H. M. Peeters (2017), 'How to Conceptualize and Operationalize Resilience in Socio-Ecological Systems', Current Opinion in Environmental Sustainability 28: 108-113. doi:10.1016/j.cosust.2017.09.003.

Sturmberg, J. P. and C. M. Martin (2013), Handbook of Systems and Complexity in Health (New York: Springer).

Tracy, M., M. Cerda and K. M. Keyes (2018) 'AgentBased Modeling in Public Health: Current Applications and Future Directions', Annual 
Review of Public Health 39: 77-94. doi:10.1146/ annurev-publhealth-040617-014317.

Van Belle, S. (2014), 'Accountability in Sexual and Reproductive Health: How Relations between INGOs and State Actors Shape Public Accountability - A Study of Two local Health Systems in Ghana' (PhD diss., London School of Hygiene and Tropical Medicine).

Van Belle, S., G. Wong, G. Westhorp, M. Pearson, N. Emmel, A. Manzano and B. Marchal (2016), 'Can "Realist" Randomised Controlled Trials Be Genuinely Realist?' Trials 17, no. 313. doi:10.1186/ s13063-016-1407-0.

Van Belle, S., S. Rifkin and B. Marchal (2017), 'The Challenge of Complexity in Evaluating Health Policies and Programs: The Case of Women's Participatory Groups to Improve Antenatal Outcomes', BMC Health Services Research 17, no. 687. doi:10.1186/ s12913-017-2627-z.

Vareilles, G., B. Marchal, S. Kane, T. Petric, G. Pictet and J. Pommier (2015), 'Understanding the Motivation and Performance of Community Health Volunteers Involved in the Delivery of Health Programmes in Kampala, Uganda: A Realist Evaluation', BMJ Open 5, no. 11. doi:10.1136/ bmjopen-2015-008614.
Venables, E. and U. Pellecchia (2017), 'Engaging Anthropology in an Ebola Outbreak: Case Studies from West Africa', Anthropology in Action 24, no.2: 1-8. doi:10.3167/aia.2017.240201.

Wellcome Trust (2018), 'DFID-Wellcome Joint Initiative on Epidemic Preparedness: Call for Proposal', https://wellcome.ac.uk/sites/default/files/epidemicprepWellcomearedness-social-science-researchprotocols-call-for-proposals-2018-07.pdf (accessed 14 July 2018).

WHO Regional Office for Africa (2017), Leave No One Behind: Strengthening Health Systems for UHC and the SDGs in Africa (Brazzaville: WHO Regional Office for Africa).

Wilkinson, A., M. Parker, F. Martineau and M. Leach (2017), 'Engaging "Communities": Anthropological Insights from the West African Ebola Epidemic', Philosophical Transactions of the Royal Society B: Biological Sciences 372, no. 1721. doi:10.1098/rstb .2016 .0305 .

Wong, G., T. Greenhalgh and R. Pawson (2010), 'Internet-Based Medical Education: A Realist Review of What Works, for Whom and in What Circumstances', BMC Medical Education 10, no.12. doi:10.1186/1472-6920-10-12. 